\title{
ON THE RELATIONSHIP OF THERMODYNAMIC AND PHYSICAL PROPERTIES OF POLYMERS WITH ICE ADHESION
}

\author{
by
}

\author{
H. Murase AND K. NANISHI
}

Kansai Paint Co Ltd, Osaka, Japan

\section{ABSTRACT}

The purpose of this work is to study the relationship of energetic and physical properties of polymetric materials with ice adhesion, and to develop the material to prevent ice adhesion. From various parameters of water and ice, dispersion and hydrogen bond contribution of surface free energy of ice were calculated. Using these values and that of contact angle formed between ice and polymer in the air and also in paraffin, work of adhesion $\mathrm{W}-\pi_{e}$ and $\mathrm{W}$ were determined respectively. The difference $W-\left(W-\pi_{e}\right)$ has made it possible to evaluate the effect of surface pressure $\pi_{e}$ on ice adhesion. On the other hand, actual adhesive strength of ice was measured. Some correlations between theoretical and observed values were found. Further, visco-elastic properties of polymers below icing temperature and temperature dependence of strain in the ice/polymer system were investigated. The results showed some characteristics of polymers which are related to molecular mobility at lower temperature, are effective in reducing the adhesive strength to ice.

Numerous attempts were made to develop coating materials to prevent ice adhesion. A composite polymer composition, which has peculiar ingredients and structure, was proposed and found to provide the ability for the lowest ice adhesion. Ice preventive mechanism of the film was discussed.

\section{INTRODUCTION}

Recently there has been growing interest in and actual need for icing-preventive materials. Though the actual application of such materials is limited to some restricted regions and periods in the field of navigation, aviation and others, the problem has been serious when accidents have taken place involving human life.

This work relates to ice adhesion to polymeric substrates and consists of the following two parts:

1) Fundamental studies of ice adhesion

2) Development of ice repellent coating.

\section{FUNDAMENTAL STUDIES OF ICE ADHESION}

There are numerous papers on the thermodynamic interactions between water and substrates; however the energetic analysis by the measurement of icing contact angle has not yet been made. This is possibly due to difficulty of assessment of the surface-free energy of ice and associated problems. In the present work such problems have been solved and a method by which ice adhesion can be treated thermodynamically has been established.

\section{Thermodynamic consideration of ice adhesion}

The specific work of adhesion $W-\pi_{e}$ in the air can be represented by the correct form of the Young-Dupré relation (Dupré 1869; Fox and Zisman 1950) modified by Bangham and Razouk (1937).

$$
\mathrm{W}-\pi_{\mathrm{e}}=\mathrm{y}_{\mathrm{i}}(1+\cos \theta)
$$

where $y_{i}$ is surface free energy of ice, $\theta$ is the contact angle of ice/substrate and $\pi_{0}$ is the reduction in surface energy of the solid resulting from adsorption of vapor from liquid being measured.

On the other hand, when the water droplet on a substrate in liquid paraffin cools into ice $\pi_{e}$ will be eliminated. Energetic equilibrium condition is represented by

$$
y_{\mathrm{Bl}}-y_{\mathrm{gi}}=y_{\mathrm{il}} \cos \theta_{1}
$$

where $y_{\mathrm{sl}} y_{\mathrm{si}} y_{\mathrm{il}}$ are interfacial free energy of substrate/paraffin, $Y_{\text {il }}$ substrate/ice and ice/paraffin, respectively. And $\theta_{1}$ is the contact angle of ice/substrate in paraffin. There are well known equations on the work of adhesion W, and interfacial free energy.

$$
\begin{aligned}
& W=y_{s}+y_{i}-y_{s i} \\
& y_{s l}=y_{s}-y_{1} \cos \theta_{2} \\
& y_{i l}=y_{i}+y_{1}-2\left(y_{i}^{d} y_{1}\right)^{\frac{1}{2}}
\end{aligned}
$$

where $y_{s}, y_{i}, \quad y_{1}$ and $y_{i}^{d}$ are surface free energy of substrate, ice, paraffin and dispersion component of ice, respectively. And $\theta_{2}$ is contact angle of paraffin on a substrate. From the equations $2,3,4$ and $5 \mathrm{~W}$ is expressed by

$$
W=y_{i}\left(1+\cos \theta_{1}\right)+y_{1}\left(\cos \theta_{1}+\cos \theta_{2}\right)-2\left(y_{i}^{d} y_{1}\right)^{\frac{1}{2}} \cos \theta_{1}
$$

Using Equation 6, work of adhesion $\mathrm{W}$ can be determined by measurement of contact angles $\theta_{1}$ of ice/substrate in paraffin and $\theta_{2}$ of paraffin on a substrate in the air and from surface free energy of ice and paraffin.

\section{Calculation of surface free energy of ice}

Fowkes (1964) determined dispersion and hydrogen bond components of water at $20^{\circ} \mathrm{C} 21.8$ and $51.0 \mathrm{~mJ} / \mathrm{m}^{2}$, respectively. Surface and interfacial free energy of ice and ice/water at $0^{\circ} \mathrm{C}$ are determined as 109.0 and $33.0 \mathrm{~mJ} / \mathrm{m}^{2}$ by Hobbs (1974).

On the other hand, the heat of vaporization of water at $0^{\circ} \mathrm{C}$ is $44.9 \mathrm{~kJ} / \mathrm{mol}$ and latent heat of freezing 6.0 $\mathrm{kJ} / \mathrm{mol}$. These internal energies must correspond to the surface contribution of 75.6 and $33.0 \mathrm{~mJ} / \mathrm{m}^{2}$, respectively. Dispersion energy can be expressed (Tabor 1978) by the work required to separate the adhered parallel plates infinitely.

$$
E=\int_{h o}^{\infty} f d h=A / 12 \pi h_{0}^{2}
$$

where $\mathrm{E}$ is dispersion energy, $\mathrm{f}$ is attractive force per unit area, $h_{0}$ is distance between molecules, $A$ is Hamaker constant. This energy is equivalent to cohesive energy $2 y$ and $h$ will be proportional to one-third power of molar volume. Then $y$ is proportional to two-third power of molar volume $\mathrm{V}_{\mathrm{m}}$. By the use of this relationship dispersion component of water and ice at any temperature can be calculated. Assumed all heat of deicing involved in the contribution from dissociated hydrogen-bond of ice, dispersion and hydrogen bond energy at $0^{\circ} \mathrm{C}$ will be 20.59 and $88.41 \mathrm{~mJ} / \mathrm{m}^{2}$, respectively. Moreover, vaporization 


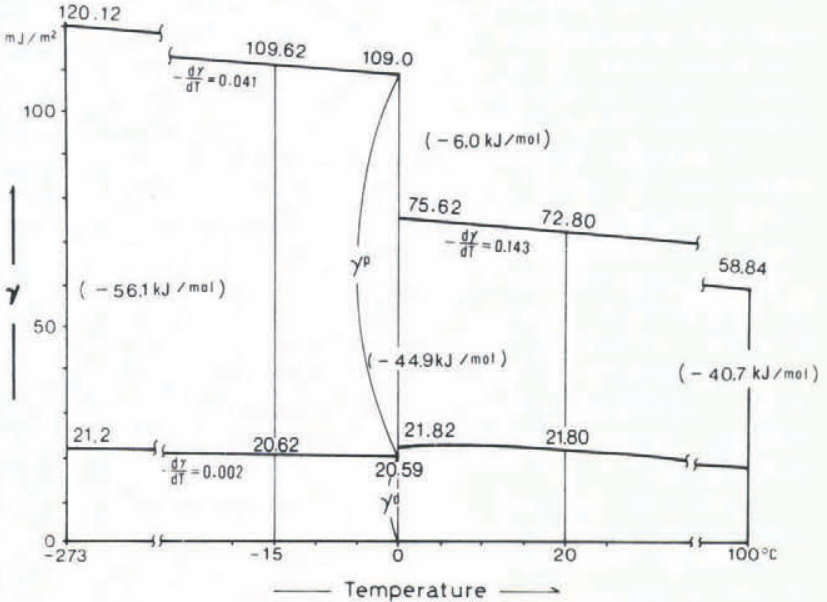

Fig.1. Dispersion and hydrogen bond components of surface free energy of water and ice.

energy at $\mathrm{O} \mathrm{K}$ is $56.1 \mathrm{~kJ} / \mathrm{mol}$. The values at an arbitary temperature can be calculated by interpolation. These relationships are shown in Figure 1. On the other hand, surface free energy of liquid paraffin (Witco chemical, Kaydol) was determined by Wilhelmy-Plate method (Klungness 1981) at $20^{\circ} \mathrm{C}$ and pendant drop method at $20^{\circ} \mathrm{C}$ and $-15^{\circ} \mathrm{C}$.

\section{EXPERIMENTAL}

\section{Materials}

Polymeric materials used in this investigation are listed in Table 1 . Resins No 1 to 13 were coated by solidification from solution on $2 \mathrm{~mm}$ thick aluminum plates cut into $70 \times 90 \mathrm{~mm}$ for the measurement of shear strength, and on the $10 \mathrm{~mm}$ thick stainless steel plates of the same size for the tensile measurement. Plastic plates of No 14 to 22 were cut into test panels in the same size described above and were adhered to $10 \mathrm{~mm}$ thick stainless steel plates for the two kinds of measurements.

\section{Apparatus and test methods}

a) For the measurement of contact angle of icing we used a goniometer (Kyowa Kaimenkagaku) consisting essentially of a contact angle meter, TV monitoring system and circulating bath for the temperature regulation. Test pieces were made in the size of $25 \times 8 \times 3 \mathrm{~mm}$. Resinous test pieces are used without treatment, whereas plastic test pieces are cleaned 3 times with distilled deionized water and finally with methanol. Test piece prepared is set in a pyrex-cell $(30 \times 20 \times 14 \mathrm{~mm})$. Then contact angles of water and ice formed on the polymeric substrates are measured at $20^{\circ} \mathrm{C}$ and $-15^{\circ} \mathrm{C}$ in the air and in paraffin, respectively. For the droplet, distilled deionized water is used and its volume is $50 \mu$.

b) For the measurement of adhesive strength of ice we developed a new programming test apparatus for the measurement of the force of ice adhesion with good accuracy and reproducibility. The apparatus consists essentially of a temperature regulated chamber, in which specimen panels are mounted firmly on a base turn-table, a driving device which generates "pull and push" force connected to a load cell, a process controller and a recorder. Stress cycles, cooling-heating schedule can be programmed freely.

\section{Measurement of shear strength}

The metal ring with inside section area $5 \mathrm{~cm}^{2}$, height $1.5 \mathrm{~cm}$ is set on polymer surface of test plates and precooled for 90 minutes at predetermined temperature, then $2 \mathrm{ml}$ of $5^{\circ} \mathrm{C}$ distilled-deionized water is poured in the ring. After keeping for 3 hours at that temperature shear strength of ice adhesion is measured.

Measurement of tensile strength

The apparatus consists of an attachment of stainless steel with $10 \mathrm{~cm}^{2}$ cross sectional area $30 \mathrm{ul}$ of distilled-deionized water is sandwiched between the specimen and a polymer substrate so as to form an ultra-thin layer $(30 \mu \mathrm{m})$ of water. The whole apparatus is then refrigerated to predetermined temperature for 3 hours at that temperature. Then tensile strength is measured.

The work of adhesion $W-\pi_{e}$ and $W$ for different polymers can be seen in Figure 2 . Figures 3 and 4 show the relationships of theoretical vs. observed ice adhesion by shear method, respectively.

\section{Physical properties and ice adhesion}

In order to investigate the susceptibility of physical properties of polymers to adhesive strength of ice, visco-elastic behaviour particularly below icing temperature on some polymers, using TBA (Tortional Braid Analysis, Toray Rigaku) was studied. Further, the Analysis, dependence of strain in the ice/polymer system, in which ice adhered the polymer surface, was studied with a DSA (Dynamic Strain Amplifier, Kyowa Electronic Institute).

\section{RESULTS AND DISCUSSION}

The values obtained for contact angle of ice in air were in most cases smaller than that of supercooled water, whereas contact angles in paraffin were not so characteristic.

TABLE 1. POLYMERIC MATERIALS USED IN THE INVESTIGATION.

\begin{tabular}{rlll}
\hline No & Sign & \multicolumn{1}{c}{ Polymer } & Manufacturer and Product \\
\hline 1 & IBA & P-i-butylmethacrylate & Mitsubishi Rayon, BR-101 \\
2 & NBA & P-n-butylmethacrylate & Mitsubishi Rayon, LR-1215 \\
3 & MMA Polymethylmethacrylate & Mitsubishi Rayon, BR-85 \\
4 & EMA & Polyethylmethacrylate & Mitsubishi Rayon, BR-90 \\
5 & PST & Polystyrene & Mitsubishi Monsant, HH-103 \\
6 & PES & Polyester & Nihon Gosei, \#220 \\
7 & VAC & Polyvinylacetate-chloride & Union Carbide, VAGH \\
8 & PUR & Acryl-Polyurethane & Kansai Paint, PG-80 \\
9 & ECL & Ethylcellulose & Wako Pure Chemical, 49\% ethoxy \\
10 & CPR & Cellulose-propionate & Daicel Chemical, 307E-H3 \\
11 & CAB & Cellulose-acetate-butylate & Eastman Kodak, \#381-01 \\
12 & SH & Organopolysiloxane & Toray Silicone, SH-237 \\
13 & PRX & Organopolysiloxane & Toray Silicone, PRX-305 \\
14 & PVC & Polyvinylchloride & Takiron, \#604 \\
15 & PCB & Polycarbonate & Asahi Glass, Lexan \\
16 & NYL & Nylon-66 & Toray, CM-300 1N \\
17 & PMA & Polymethylmethacrylate & Mitsubishi Rayon, Acrylite-S \\
18 & PE & Polyethylene & Shin-Kobe Electric, Polysheet EL \\
19 & PP & Polypropylene & Shin-Kobe Electric, Enpla \\
20 & TFE & Polytetrafluoroethylene & Nippon Valqua, Valflon \\
21 & FCP & TFE-ethylene copolymer & Asahi Glass, Aflon COP \\
22 & PF & Solid paraffin & Wako Pure Chemical, MP 68 70 ${ }^{\circ C}$ \\
& & & \\
\hline
\end{tabular}




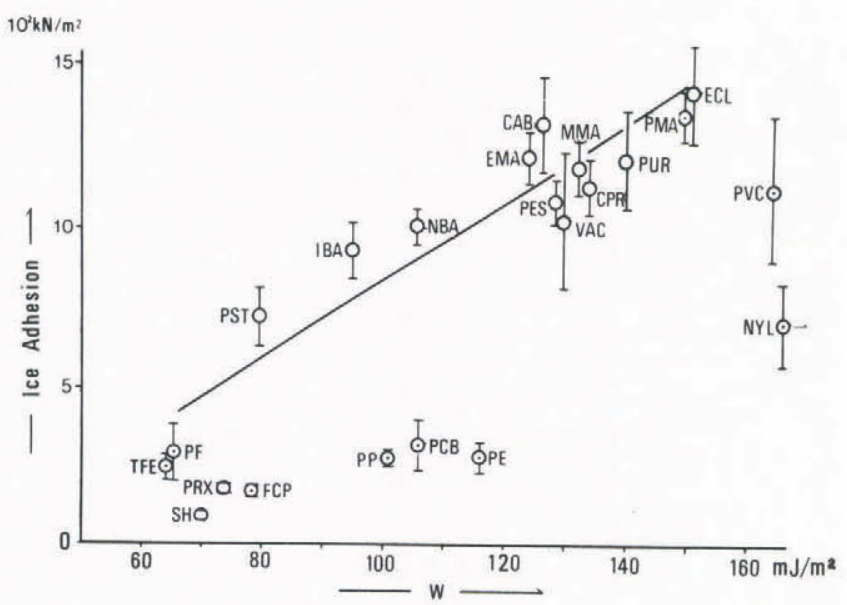

Fig.2. Work of adhesion between polymers and ice determined thermodynamically at $-15^{\circ} \mathrm{C}$.

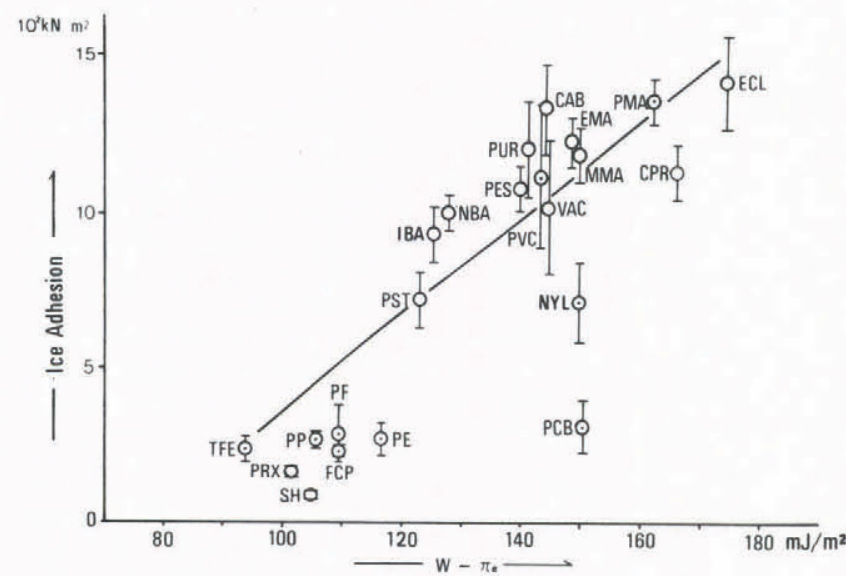

Fig.3. Relationship of work of adhesion (W $-\pi_{e}$ ) vs observed adhesive strength of ice in shear at $-15^{\circ} \mathrm{C}$.

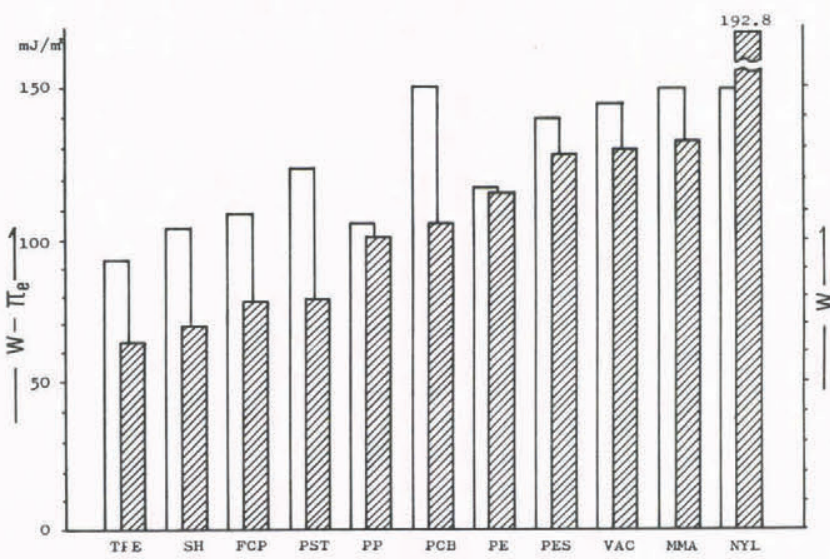

Fig.4. Relationship of work of adhesion (W) vs observed adhesive strength of ice in shear at $-15^{\circ} \mathrm{C}$.

$\pi_{e}$ must be obtained from the difference $W-\left(W-\pi_{e}\right)$. As can be seen, $\pi_{e}$ values are negative with a few exceptions, although from a theoretical viewpoint, these must take positive values. A possible explanation for this is the very strong, momentary interaction of supercooled water molecules with the adsorbed ones on icing. It has been revealed, that the value for $\pi_{e}$ ignored by Landy and Freiberger (1967) can be evaluated by this method.

On the relationship of theoretical vs, observed interaction by shear fracture, considerable linearity was obtained, although so many other properties of polymer were not taken into consideration. The adhesive strength of ice to such as polymers; polycarbonate and Nylon-66 have deviated exceptionally from the values expected from theoretical level. It is presumed, that the resulting lower values cause a liquid-like transition layer suggested by Bowden and Tabor (1950), and Weyl (1951).

Generally, it can be said that polymers having lower values for $W$ result lower ice adhesion to that. By the tensile method at $-15^{\circ} \mathrm{C}$, cohesive fracture accurred in most cases. The measured values are thought to be valid only when the measurement is made at $-10^{\circ} \mathrm{C}$ and with polymers of low surface energy. Temperature dependence of ice adhesion was studied. The gradient obtained in the group of acrylic polymers is much larger than that of energetic values calculated, whereas with fluoro-, silicone- and olefinic resins, temperature dependency is not so conspicuous.

As can be seen in Figure 5 and Table 2, the susceptibility of polymer to icing depends on its visco-elastic behaviour in a low temperature zone as well as on the properties of surface. It is difficult to differentiate the contribution of surface energy and visco-elastic properties to ice-mitigative effects, because low energy polymers generally have low glass-transition temperatures. However, it is clear, that higher rigidity or higher glass-transition temperature such as IBA, TFE and solid paraffin (PF) at low temperature affects to reduce ice adhesion negatively. DSA investigation (Figure 6) showed that the magnitude of contraction strain of the film in the vicinity of icing interface is proportional to tensile strength of ice adhesion. From the results mentioned above, the physical characteristics of polymers involved in molecular mobility can be a necessary condition to reduce ice adhesion.

\section{DEVELOPMENT OF ICE REPELLENT COATING}

Through the fundamental experiments, some relationships of energetic and physical properties of polymers with ice adhesion were revealed. From the results, it is presumed that any polymeric material with an ordinary structure cannot provide the performance to prevent from ice adhesion completely, even if the polymer characteristic found are set up optimum. As the results of investigations from various aspects, a composite material, to which ice adhesion can be remarkably prevented, was found.

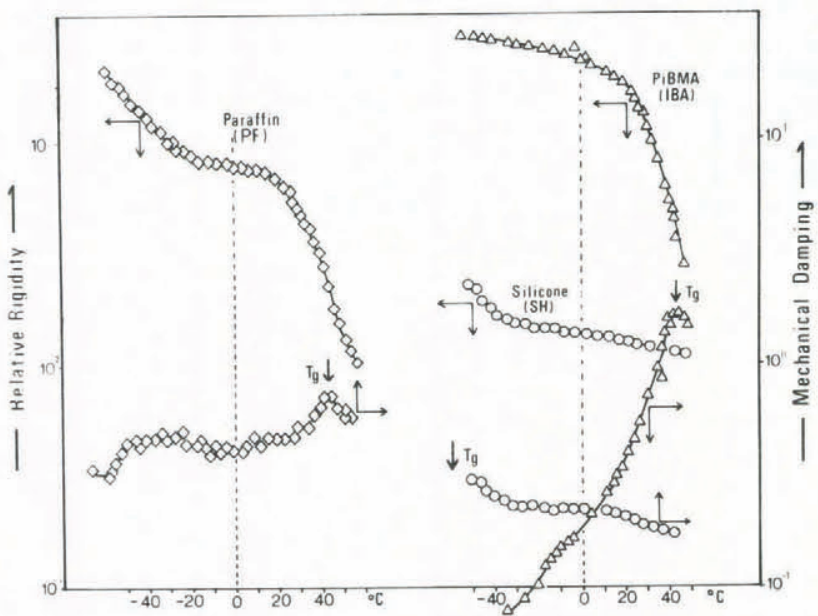

Fig.5. Mechanical damping and relative rigidity of polymers at low temperatures.

TABLE 2. CORRELATION OF WORK OF ADHESION (W), VISCO-ELASTIC PROPERTY (Tg) VS ICE ADHESION.

\begin{tabular}{lllc}
\hline Polymers & $\mathrm{W}\left(\mathrm{mJ}^{\mathrm{m}} / \mathrm{m}^{2}\right)$ & $\mathrm{Tg}(\mathrm{K})$ & Ice Adhesion $\left(\mathrm{kN} / \mathrm{m}^{2}\right)$ \\
\hline PiBMA & 94.6 & 317 & 9.37 \\
Paraffin & 65.2 & 316 & 3.04 \\
Silicone & 69.9 & $233>$ & 0.96 \\
\hline
\end{tabular}




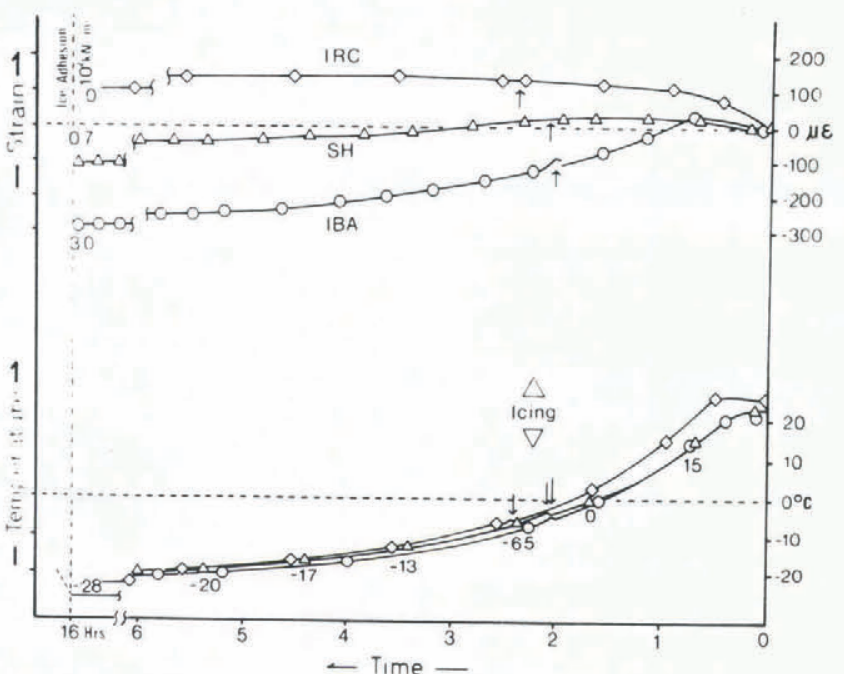

Fig.6. Temperature dependence of strain in ice/polymer system and tensile strength of ice adhesion.

Composition and mechanism for prevention from ice adhesion

Basic studies of mechanism of icing from viewpoints of thermodynamic and physical factors were made. In the course of numerous attempts, it has been found that ice adhesion can be almost completely prevented by the synergetic effect resulting from the combined use of an organopolysiloxane resin and alkali metal compound. The trial product of this coating material is tentatively named IRC. The film made from this composite materials has characteristic surface properties, and shows amphibious nature; hydrophobic and hydrophilic.

The organopolysiloxane resin has a chain of hydrocarbon atoms arranged on its surface and thus is low in surface energy resulting hydrophobicity. This resin contains a small amount of a polar ingredients prone to form hydrogen bonds. This is the reason for the formation of the polymers considerably amenable to icing. Alkali metal compound, especially containing lithium atoms, shows strong hydrophilicity. The lithium ion has a small Pauling radius $(0.06 \mathrm{~nm})$ so that the hydration energy is great as $5.23 \mathrm{x}$ $10^{2} \mathrm{~kJ} \mathrm{~mol}^{-1}$ and acts therefore as a hydrogen bond breaker. It is confirmed by Hiraoka and Yokoyama (1982), that the four oxygen atoms from water molecules and two oxygen atoms contained in a carboxylic residue associate together to form the structure of octahedron coordination. The water molecules thus hydrated on lithium ion are said the bound water or non freezing water. Schematic representation of the structure is shown in Figure 7. Around the bound water, some layers of water molecules so-called the restrained water are arranged, and surrounded by the free water. Each three types of water will behave differently at icing temperature. It is assumed that structural

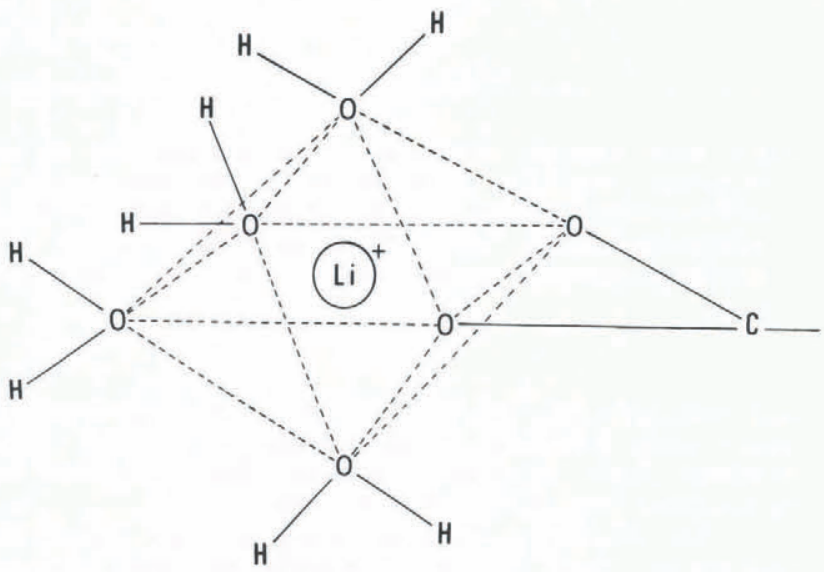

Fig.7. Schematic representation of bound water hydrated on a lithium ion.

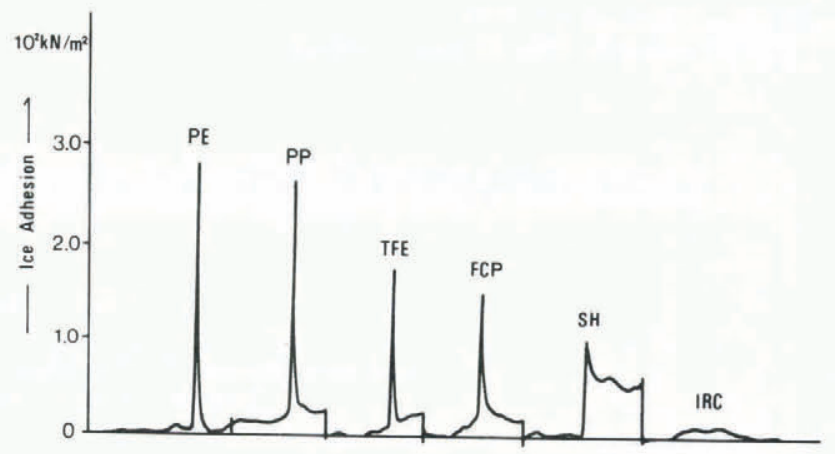

Fig.8. Adhesive strength of ice to IRC in comparison with some low energy polymers (in shear at $-15^{\circ} \mathrm{C}$ ).

and energetic differences thereof and synergetic effect from silicone matrix result in preventing ice adhesion. DSC analysis of this film showed that the water absorbed in the film up to $8 \%$ does not have a definite freezing point, and at the $15 \%$ the water showed a broader freezing range, namely $0 \sim-28^{\circ} \mathrm{C}$. furthermore, the relaxation times of the equilibrium water absorbed in freezed film at $-20^{\circ} \mathrm{C}$ were studied by Pulsed NMR. It was clear that the structure of water molecules are in the state "restrained". The adhesive strength of ice to the film in comparison with other materials of low ice adhesion is shown in Figure 8 . Monitoring tests are under way in many fields of application.

\section{REFERENCES}

Bangham D H, Razouk R I 1937 Transactions of the Faraday Society (33): 1459

Bowden F P, Tabor D 1950 The friction and lubrication of solids. New York, Oxford University Press

Dupré A 1869 Théorie méchanique de la chaleur. Paris, Gautier-Villars

Fowkes F M 1964 Attractive forces at interfaces. Industrial and Engineering Chemistry 56: 40

Fox H W, Zisman W A 1950 Thespreading of liquids on low energy sufaces. Journal of Colloid Science 5: 514-531

Hiraoka K, Yokoyama T 1982 The 20th symposium on polymer and water. Tsukuba, The Society of Polymer Science

Hobbs P V 1973 Icephysics. Oxford, Clarendon Press

Klungness J H 1981 Measuring the wetting angle and perimeter of single wood pulp fibers, a modified method. Tappi 64(12): 65-66

Landy M, Freiberger A 1967 Studies of ice adhesion. Colloid and Interfacial Science 25: 231-244

Tabor D 1978 The solid surface. Physical Science Bulletin 29: $521-525$

Weyl W A 1951 Surface structure of water and some of its physical and chemical manifestations. Journal of Colloid Science 6: 389-405 